\title{
ECOLOGIA \\ ORGANIZACIONAL: \\ implicações para a gestão e algumas pistas para a superação de seu caráter anti-management
}

\author{
Miguel Pina e Cunha \\ Mestre em Comportamento Organizacional pelo Instituto Superior de Psicologia Aplicada \\ (ISPA - Portugal), Doutor em Marketing pela Universidade de Tilburg (Holanda) e \\ Professor Auxiliar na Faculdade de Economia da Universidade Nova de Lisboa. \\ E-mail:mpc@feunix.fe.unl.pt
}

\section{RESUMO}

O artigo mostra que a ecologia organizacional é um dos domínios teóricos mais em evidência no atual panorama das ciências organizacionais. Ele está estruturado em torno da análise teórica de duas questões centrais: a) Quais as razões do desenvolvimento súbito da ecologia organizacional e de seu elevado consenso paradigmático? b) É a ecologia organizacional uma abordagem realmente anti-management? Apresentam-se as razões que conduziram à emergência da ecologia organizacional, seguindo-se a exploração de algumas de suas implicações para a gestão de empresas, concluindo-se com algumas pistas para a superação de seu caráter anti-management.

\section{ABSTRACT}

The article shows that organizational ecology is a theoretical realm most in evidence in recent organizational science. It deals with two main questions of theoretical analysis: a) Which are the reasons for the sudden development of organizational ecology and its high paradigmatic consensus? b) Is organizational ecology a real antimanagement approach? Reasons that lead to prominence of organizational ecology are presented and followed by explanations of some consequences in enterprise management, including some gists in order to surpass its anti-management profile.

PALAVRAS-CHAVE

Ciência organizacional, ecologia organizacional, teoria da contingência, teorias organizacionais anti-management.

KEY WORDS

Organizational science, organizational ecology, contingency theory, anti-management theories of organization. 


\section{INTRODUÇÃO}

A ecologia organizacional pode ser entendida como um dos domínios teóricos mais em evidência no panorama recente das ciências organizacionais. As razões para tanto são bastante diversas e, por vezes, contraditórias: a relevância crescente que a ecologia organizacional vem assumindo na teoria das organizações desde a publicação do texto seminal de Hannan e Freeman (1977); o caráter de consenso paradigmático que parece caracterizá-la, em contraponto ao estado de fragmentação patente na maioria das demais subdisciplinas da teoria das organizações (Pfeffer, 1993); o ataque violento do qual acaba de ser alvo no livro de Lex Donaldson (1995), sob o título expressivo de American antimanagement theories of organization. Esse conjunto de razões parece tornar não apenas atual, mas também premente, uma reflexão em torno de duas questões centrais. Quais as razões do desenvolvimento súbito da ecologia organizacional e do seu elevado consenso paradigmático? É a ecologia organizacional uma abordagem realmente anti-management?

Este artigo será estruturado em torno da análise teórica dessas duas questões. Primeiramente, discutem-se as razões que conduziram à emergência da ecologia organizacional. Em seguida, exploram-se algumas possíveis implicações da ecologia organizacional para a gestão de empresas. Por fim, são apresentadas algumas pistas para a superação do seu caráter anti-management. Não serão expostas aqui as linhas mestras da teoria ecológica, as quais podem ser encontradas, por exemplo, e para apenas fazer referência a alguns textos publicados no Brasil, nos trabalhos de Fischmann (1972), de Zaccarelli, Fischmann e Leme (1980) ou de Cunha (1993).

\section{O BOOM DA ECOLOGIA ORGANIZACIONAL}

O surgimento da ecologia organizacional, inicialmente conhecida como ecologia das populações organizacionais, é habitualmente identificado com a publicação, em 1977, do artigo de Michael T. Hannan e John Freeman (1977), intitulado "The population ecology of organizations". Com ele nascia uma abordagem que, nos anos seguintes, logrou um crescimento fulgurante e um lugar de grande destaque na teoria organizacional contemporânea ${ }^{1}$.
Tendo em conta que Lex Donaldson (1995) critica violentamente a abordagem ecológica, por considerá-la uma teoria anti-management, torna-se necessário contrapor dois corpos de argumentação: a própria apreciação crítica de Donaldson, isto é, por que razão pode a teoria ecológica ser tomada como antigestão, e a argumentação pró-ecológica, com a qual serão analisados os motivos que transformaram uma teoria pretensamente

\section{A ecologia organizacional dedica-se ao estudo de um nível de análise habitualmente} ignorado na teoria organizacional, isto é, o das populações de organizações.

crítica para os gestores num dos paradigmas mais populares no domínio da teoria organizacional.

A seguir, haverá uma apresentação breve desses dois grupos de argumentos.

\section{A natureza anti-management da ecologia organizacional}

Numa crítica feroz à proliferação de paradigmas na teoria organizacional, Donaldson (1995) considera a ecologia organizacional como a abordagem que mais frontalmente desafia a perspectiva contingencial, o que a transformaria na mais anti-management de todas as teorias assim classificadas que surgiram na recente cena científica americana (grupo que também engloba a perspectiva institucional, a dependência de recursos e a economia organizacional).

$\mathrm{Na}$ argumentação apresentada por Donaldson, que parte das premissas básicas da teoria, ressaltam-se os seguintes apontamentos:

a) na teoria ecológica, o ambiente externo é "proativo", cabendo aos gestores um papel passivo e de resistência à mudança induzida pelo exterior;

b) o fato de o processo de seleção das organizações se desenvolver numa lógica supra-organizacional retira relevância e pertinência ao papel adaptativo do gestor tal como concebido noutras teorias (principalmente na contingencial);

c) ao aceitar que são predominantemente as populações que mudam, e não as organizações (vide o conceito de inércia estrutural), a teoria ecológica não se mostra capaz de propor um conjunto de prescrições para a atividade de adaptação organizacional; 
d) a transposição da teoria darwiniana para o domínio das organizações não se processa sem problemas, parecendo a teoria ecológica mostrar-se pouco sensível a esse tipo de argumento. Embora possa constituir uma metáfora com francas potencialidades para o estudo das organizações (o que será talvez provado pela sua longa história em teoria organizacional), a perspectiva biológica não deve ser decalcada sem alguma cautela para o domínio das organizações (as quais, desde logo, e a título de exemplo, não herdam qualquer tipo de patrimônio genético).

Como facilmente se depreende dessas argumentações críticas, a teoria ecológica parece, de fato, encerrar alguns focos anti-management. O papel do gestor é diminuído por referência à influência do ambiente externo, a racionalidade organizacional dilui-se na racionalidade populacional, a metáfora biológica invalida a utilidade potencial de outras metáforas que com ela talvez se pudessem combinar (sobretudo a política), as tentativas de aproximação a outras abordagens da adaptação organizacional (notadamente à abordagem contingencial dominante) são simplesmente inexistentes. Esse cerco sobre um conjunto de premissas relativamente rígidas e bem distintas do paradigma dominante não será de somenos importância para o reforço da coesão da ecologia organizacional.

Não deixa de ser surpreendente verificar que, mesmo em face dessa barragem crítica, a teoria ecológica tem arregimentado um conjunto de adeptos que dela fazem um campo subdisciplinar ativo e inserido num conjunto de asserções profundas, a ponto de Pfeffer (1993) considerá-la um exemplo de coesão paradigmática num domínio tão pouco coeso como o da teoria organizacional. Na seção seguinte, serão analisadas as razões que tornaram tão popular uma subdisciplina que parece desafiar de forma evidente o saber acumulado no campo científico de que participa.

\section{Razões para a afirmação da ecologia organizacional}

A crítica de Donaldson à ecologia organizacional nos obriga a responder a uma questão que dela decorre: se a teoria ecológica se revela tão perniciosa para o desenvolvimento da teoria organizacional e, principalmente, para o seu relacionamento com os gestores e a gestão, como explicar o seu sucesso e crescimento, traduzidos, por exemplo, no consenso paradigmático que nela observa Pfeffer?

Várias possibilidades de explicação podem ser apresentadas.

A primeira refere-se ao fato de a ecologia organizacional dedicar-se ao estudo de um nível de análise habitualmente ignorado na teoria organizacional, isto é, o das populações de organizações. Acontece que as abordagens organizacionais dominantes analisam a organização como se a sua ação fosse independente da influência e da interação com o am-

\section{A ecologia organizacional pode ser vista} como um sinal dos tempos. Um sinal de uma época competitiva, a ponto de se levantarem vozes sobre a justeza e as consequiências
da ideologia da competição.

biente externo. Ao realçar a escassez dos recursos e a competição interorganizacional pela posse desses recursos, a teoria ecológica ajuda a compreender fenômenos normalmente esquecidos ou ignorados, como o nascimento e a morte das organizações, os padrões evolutivos das populações organizacionais, as limitações dos gestores na manutenção das capacidades adaptativas das empresas, a força da inércia, etc. Essas questões, embora centrais, tendem a ficar de fora das preocupações das teorias alinhadas pelo diapasão dominante, mais dedicadas ao estudo do alinhamento de alterações adaptativas sucessivas e de sucesso, e analisadas no contexto de designações como as de mudança organizacional ou desenvolvimento organizacional.

Uma segunda explicação seria a de que a teoria ecológica representa um passo significativo na aplicação da metáfora biológica às organizações. Se a evolução das espécies deve ser entendida no âmbito das populações, então o mesmo parece fazer sentido no que se refere à compreensão da evolução organizacional. Dada a capacidade apelativa da metáfora biológica, não é de todo surpreendente que a ecologia organizacional, com a sua visão renovadora e longitudinal, tenha sido capaz de atrair um grande número de adeptos.

Por fim, restaria o argumento de que a experiência comum mostra que as empresas têm dificuldade em 
mudar, que o cenário hipercompetitivo recrudesce a dependência de recursos, que a concorrência empresarial se parece, cada vez mais, com uma luta pela vida em muitos aspectos semelhante àquela que envolve organismos vivos. Nesse aspecto em particular, a ecologia organizacional pode ser vista como um sinal dos tempos. Um sinal de uma época competitiva, a ponto de se levantarem vozes sobre a justeza e as consequiências da ideologia da competição - vide Grupo de Lisboa (1994)². lizada, é de se prever que ataques semelhantes ao de Donaldson se intensifiquem. O problema da visibilidade das implicações práticas é, de resto, e tal como observado por McKelvey e Aldrich (1983), um problema comum no nível macro de análise organizacional, o que justifica que as implicações práticas da investigação realizada sejam regularmente avaliadas em termos de capacidade prescritiva.

Embora as implicações da ecologia organizacional possam ser estudadas em vários níveis de análise (organizacional, populacional, comunitário), serão analisadas aqui suas implicações no nível organizacional. Antes, porém, será apresentada uma breve análise do papel do gestor segundo a teoria ecológica.

\section{contexto, mas não a ponto de sua ação ser determinada pelo ambiente externo.}

Os argumentos apresentados talvez ajudem a perceber a pujança da teoria ecológica e a atração que ela tem gerado na comunidade acadêmica. $\mathrm{O}$ seu caráter anti-management será, por sua vez, o resultado de um conflito de interesses entre a comunidade científica e a profissional: uma teoria não é necessariamente má por não se adequar aos interesses de um determinado grupo profissional e por não lhe reconhecerem os créditos normalmente considerados nas sociedades ocidentais. No restante do artigo, em todo caso, tomar-se-á como aceitável o ponto de partida de Donaldson, segundo o qual as teorias organizacionais devem se revestir de utilidade para a gestão e, por conseguinte, para o desenvolvimento humano. Procurar-se-á, assim, ensaiar breves tentativas de resposta a duas diferentes questões: A teoria ecológica apresenta implicações válidas para a gestão de organizações? E como aproximar a teoria ecológica das teorias de gestão para gestores?

\section{ECOLOGIA ORGANIZACIONAL E GESTÃO}

O objetivo desta seção é o de analisar as possíveis conseqüências da ecologia organizacional para a gestão de organizações. A utilidade potencial da teoria ecológica para a prática da gestão e administração de empresas parece revelar-se um problema crucial para o futuro da subdisciplina, uma vez que, arrefecido o entusiasmo inicial e se não forem visíveis algumas implicações práticas decorrentes da investigação rea-

\section{O papel do gestor na teoria ecológica}

Tendo por base as referências sobre o tema no livro Organizational ecology, de Hannan e Freeman (1989), dir-se-ia que em nenhuma outra teoria organizacional lhe é conferido um papel tão limitado. Tome-se, como exemplo, a seguinte citação: “(...) mesmo analisando este caso no qual um único indivíduo desempenhou um papel dominante, Chandler não atribuiu a primazia causal à realização individual. $\mathrm{O}$ autor tornou claro que o conjunto de mudanças técnicas, legais e sociais conduziu o desenvolvimento de novos modos de organização" (Hannan e Freeman, 1989, p. 41).

Ou seja, o papel do gestor, mesmo quando parece importante, é, segundo a teoria ecológica, menos importante do que pode parecer. O papel do gestor é limitado por um conjunto de quatro fatores, ou melhor, "pelo menos quatro", para usar as palavras de Hannan e Freeman (1989, p. 41): a) a forma organizacional, que constrange e conduz o comportamento individual; b) a escassez dos recursos, que dificulta a gestão da mudança; c) o padrão de competição inter e intraorganizacional, que reduz as possibilidades de escolha e faz com que as pressões competitivas amplifiquem o efeito de outros fatores; d) o efeito das limitações à racionalidade, da forma como são apresentadas pelos psicólogos cognitivos.

Por mais poderosas que sejam essas limitações, elas não conseguem ser totalmente convincentes do ponto de vista da análise organizacional. A seguir, elas serão analisadas uma a uma:

a) A forma organizacional constrange, obviamente, o 
comportamento individual, mas não elimina a incerteza subjacente à sua variabilidade. A perspectiva interacionista (Schneider, 1983) e a literatura relativa à arena política (vide Crozier e Friedberg, 1977) mostram bem que assim é, ilustrando respectivamente a reciprocidade patente nas influências indivíduo-organização e a possibilidade de os indivíduos jogarem a seu favor com as áreas de incerteza inevitavelmente existentes na ação organizada.

b) Pode-se postular que é justamente por serem escassos os recursos que a mudança é necessária, embora não se lhe queira negar a dificuldade. Se a gestão da mudança fosse fácil e normalmente bem-sucedida, então a todos os gestores corresponderia o papel de "anti-heróis da gestão", típico da teoria ecológica. Ora, o caráter "heróico" de alguns gestores decorre precisamente do fato de competirem por recursos escassos. Tal como indicado por Verhallen (1984), o valor das coisas é tanto menor quanto mais abundantes elas forem.

c) Embora as escolhas dos gestores possam ser limitadas por todo um conjunto de fatores que escapam ao seu controle, é a sua capacidade de gerir aquilo que está sob seu controle mais direto (o ajustamento estratégia/estrutura/processo ao ambiente externo) ou menos direto (a ação política sobre o ambiente externo) que distingue o bom do mau gestor.

d) As limitações à racionalidade não fazem dos gestores seres irracionais, isto é, desprovidos de razão. Essas limitações apenas indicam o fato de os gestores se contentarem com escolhas satisfatórias e de recorrerem a comportamentos que são por vezes tomados, equivocadamente, como irracionais, caso da intuição (Garcia-Marques, 1995).

Da discussão anterior, parece poder-se concluir que o papel do gestor é esvaziado da sua importância de uma forma talvez excessiva. Não sendo necessariamente "heróis", os gestores não devem ser tratados como "anti-heróis": eles são atores organizacionais constrangidos pelo contexto, mas não a ponto de sua ação ser determinada pelo ambiente externo. Em alguns casos, eles conseguem mesmo (devida ou indevidamente) uma ampla latitude de decisão, chegando até mesmo a pôr em risco a própria organização (vide o caso do corretor Nick Leeson no banco Barings).

A redução do papel dos gestores, decorrente das asserções profundas da teoria - as quais já foram, de resto, alvo de crítica (vide Young, 1988) -, é outro dos pontos que mais contribui para a defasagem entre a teoria ecológica e as teorias correntes da gestão de empresas. Trata-se, com toda a probabilidade, de um ponto merecedor de discussão futura: mesmo aceitando que o contexto organizacional e ambiental constrange a ação dos gestores, é difícil aceitar que o processo de influência entre o contexto e o gestor se desenrole num só sentido: do contexto para o gestor.

\section{Mesmo aceitando que o contexto organizacional} e ambiental constrange a ação dos gestores, é difícil aceitar que o processo de influência entre

\section{o contexto e o gestor se desenrole num só sentido: do contexto para o gestor.}

\section{Algumas implicações para a gestão}

Embora não se trate do nível de análise por excelência da ecologia organizacional, essa abordagem consegue fornecer um leque de conclusões importantes para a análise e gestão das organizações.

Lógica sistêmica: a ecologia organizacional realça o papel do ambiente externo ao mesmo tempo que subalterniza o papel dos gestores. Essa perspectiva é contrária, repare-se, àquela normalmente seguida na ciência organizacional, que consiste em estudar as organizações como criações do gestor e, portanto, como "extensões" dos seus processos de decisão. Embora não negando o papel do gestor nem pondo em questão a importância das suas decisões, parece necessário desenvolver uma teoria capaz de ver as ações da organização de forma mais abrangente: de cima para baixo, mas também de baixo para cima, de dentro para fora, mas também de fora para dentro. Tudo isso, note-se, em simultâneo, como num sistema autenticamente aberto.

Monitoria ambiental: a ecologia organizacional destaca o papel do ambiente externo e torna explícita a necessidade de despender cada vez mais tempo com tarefas de monitoria ambiental. Essa idéia, que vai ganhando cada vez mais adeptos, obriga a gerir (e não apenas a conceber) as organizações como sistemas abertos. A teoria ecológica, articulada com uma perspectiva funcionalista, confirma como necessária uma visão interacionista das organizações: em vez de entender o sucesso, ou o fracasso, como resultado do mérito do 
gestor ou da "crueldade" da seleção, o papel do gestor e o seu mérito devem ser avaliados cada vez mais pela capacidade demonstrada em articular de forma harmoniosa as pressões externas com as necessidades e capacidades internas. Subjacente a essa idéia, encontrase a noção de que os gestores de topo devem ser cada vez mais catalisadores da abertura ao exterior em vez de controladores intra-organizacionais.

\section{0 papel do gestor e o seu mérito devem ser avaliados} cada vez mais pela capacidade demonstrada em articular de forma harmoniosa as pressões externas com as necessidades e capacidades internas. veis. Pode haver outras explicações plausíveis (limitações de capital, problemas de eficiência, fraca capacidade de intervenção no mercado), mas é mérito da teoria ecológica ter apresentado uma explicação para as elevadas "taxas de mortalidade infantil" das organizações: segundo os dados do Ministério do Emprego e da Segurança Social de Portugal referentes aos anos $80,20,5 \%$ das empresas portuguesas têm uma duração de vida igual ou inferior a um ano. Na linha dos enunciados da teoria ecológica e de acordo com esses dados, as empresas aparentemente mais expostas às pressões seletivas são organizações mais jovens e presumivelmente menores. Ações como apoio às empresas recém-nascidas, cria-

Análise dos efeitos da dimensão: outra implicação da teoria ecológica relaciona-se com o impacto da dimensão no sucesso empresarial. À idéia de que as organizações de pequena dimensão são aquelas que se encontram mais bem aparelhadas para fazer face à competição ("small is beautiful"), Hannan e Freeman (1984) contrapõem a idéia de que as grandes organizações dispõem de vantagens não-negligenciáveis. $\mathrm{O}$ enunciado de Hannan e Freeman reveste-se de particular importância porque explicita as vantagens da dimensão e da inércia. $\mathrm{O}$ conceito de inércia vem por sua vez ajudar a compreender a dominância do modelo burocrático de organização: as grandes organizações, isto é, as mais inertes, têm condições de oferecer ao consumidor produtos/serviços com menores variações qualitativas do que as pequenas organizações, menos rotinizadas e por isso com resultados eventualmente menos consistentes. É curioso notar, nessa seqüência, que um conceito tão importante como o da rotina só agora começa a ser alvo de investigação (vide Weiss e Ilgen, 1985). A elucidação da importância das rotinas organizacionais permitirá talvez explicitar até que ponto é vantajoso que as organizações sejam capazes de conjugar rotinas bem-ajustadas com uma aprendizagem ativa.

A vulnerabilidade das organizações jovens: o estudo das organizações numa lógica populacional permitiu também dar a devida importância à questão da vulnerabilidade inicial ("liability of newness"): as organizações mais jovens apresentam taxas de insucesso mais elevadas do que as organizações mais antigas. Isso seria devido, segundo Hannan e Freeman (1984), ao fato de as organizações mais jovens não terem ainda alcançado níveis de confiança e de responsabilidade aceitá- ção de ninhos de empresas ou centros de incubação de negócios e benefícios fiscais nos primeiros anos de atividade poderão funcionar como medidas favoráveis à infância organizacional e, desse modo, contribuir para a diminuição da vulnerabilidade inicial.

Inércia e organizações: do exposto, decorre que a fase inicial é um período delicado para a vida de qualquer organização. Isso indica que as empresas devem estar preparadas para essa vulnerabilidade infantil, devendo, no período pré-natal, dotar-se de uma base de recursos suficiente para que se torne mais provável a superação da fase inicial de escassez. Em termos de apoios governamentais, parece também mais correto apoiar as organizações em dificuldades na fase inicial do seu ciclo de vida do que as organizações declinantes, as quais, em face da possível existência de níveis de inércia mais elevados, dificilmente serão capazes de inverter com sucesso o curso da sua própria queda. $\mathrm{O}$ apego a processos rotineiros poderá transformar a inércia estrutural numa fonte de desvantagem competitiva, o que obriga a questionar o papel pouco pacífico da inércia na vida das organizações. Poderão surgir, portanto, organizações com falhas permanentes, constantemente deficitárias e cuja sobrevivência não é possível a não ser à custa da injeção de capitais destinados a suprir os déficits crônicos.

Estratégia organizacional: a ecologia organizacional pode também fornecer uma contribuição relevante para o estudo da estratégia empresarial. Sendo a estratégia freqüentemente entendida como uma forma de articulação entre a organização e o ambiente externo, não deixa de ser curioso verificar que a análise estratégica se mostra vulnerável às críticas que lhe apontam aten- 
ção excessiva a processos internos, principalmente no planejamento, e aceitação de modelos estáticos de análise do ambiente externo, fundados nos princípios da estabilidade ou do equilíbrio. A ecologia organizacional poderá oferecer uma grade de análise adequada para a compreensão do dinamismo inerente à formulação, à implementação e à validação (seletiva) das estratégias organizacionais. Conforme demonstrado por Boeker (1991), a competição e o ambiente externo desempenham um papel importante na viabilidade de certos tipos estratégicos. A extensão empírica dessa abordagem poderá, em última análise, fornecer uma contribuição-chave para o desenvolvimento da perspectiva contingencial, caso seja capaz de explicitar, tendo em conta um conjunto de características organizacionais e ambientais, qual o posicionamento estratégico mais indicado em determinado tipo de ambiente externo, aqui considerado numa perspectiva dinâmica. Tal como defendido por Burgelman (1990), a integração entre as perspectivas estratégica e ecológica poderá ajudar a contextualizar a estratégia e a ultrapassar o determinismo ambiental inerente a uma visão ecológica "total", contribuindo, desse modo, para explicitar as limitações de cada uma daquelas abordagens.

\section{ORGANIZAÇÃO E CONTEXTO: UMA INTEGRAÇÃO FUNCIONALISTA}

O caminho a trilhar pela futura investigação na área da ecologia organizacional poderá passar pela aproximação à perspectiva contingencial. Essa aproximação, não sendo fácil, parece promissora. Não é fácil porque tal transição implicaria a aceitação da interação da racionalidade organizacional com a racionalidade ambiental. Note-se, em todo caso, que um dos pontos fra$\cos$ da abordagem ecológica parece radicar-se justamente na sua recusa em aceitar que os gestores procuram tomar decisões adaptativas, isto é, decisões que melhorem o ajustamento ao meio e, por conseguinte, a probabilidade de sobrevivência da organização. Se assim não fosse, seriam profundamente irracionais quer as ações da gestão de topo, quer a própria existência de gestão de topo, cujo papel limitar-se-ia, praticamente, a efeitos de representação.

Conforme se procurou demonstrar na seção anterior, a teoria ecológica apresenta uma série de implicações interessantes do ponto de vista da gestão de empresas. Essas implicações demonstram que o seu eventual caráter anti-management se radica mais nos pres- supostos de base do que na própria teoria. A abertura da ecologia organizacional aos elementos da abordagem contingencial revela-se promissora na medida em que poderá permitir a análise da interação entre as ações organizacionais individuais e o contexto ecológico em que essas ações, desejavelmente adaptativas, ocorrem.

\section{Os gestores de topo devem ser cada vez mais} de controladores intra-organizacionais.

As abordagens contingencial e ecológica seriam, desse modo, complementares: a teoria contingencial ilustraria o esforço de adaptação das organizações ao seu ambiente externo, enquanto a teoria ecológica assinalaria as razões do sucesso ou fracasso desse esforço adaptativo.

Essa tentativa de integração na análise da relação organização-ambiente externo permitiria, por exemplo, um conhecimento mais apurado da relação entre certos tipos de configurações internas e os respectivos contextos ecológicos. Tornar-se-ia possível, desse modo, analisar não apenas as configurações internas e as variáveis externas, mas também as interações entre umas e outras, bem como proceder à análise dinâmica da evolução do ambiente externo organizacional, evolução essa necessariamente co-extensiva com a evolução das formas organizacionais que lhe estão na base. Da perspectiva da adaptação organizacional ou da evolução de organizações e ambientes externos, passar-se-ia, dessa forma, à análise da co-evolução organização-ambiente externo (Baum e Singh, 1994). A idéia de co-evolução, assente num mecanismo de feedback não-linear, torna patente a atuação simultânea de processos de adaptação (estudados pela perspectiva contingencial) e de seleção (abordados pela teoria ecológica): as organizações procuram adaptar-se ao ambiente externo, mas tal esforço repercute na restante população, que lhes responde na tentativa de manter a sua própria posição adaptativa. Esses esforços adaptativos, ampliados à escala populacional, geram por vezes ciclos de feedback não-linear (por exemplo, guerras de preços) que neutralizam as tentativas de adaptação individual e tornam particularmente visível a atuação dos mecanismos de seleção. A natureza co-evolutiva da relação organização-ambiente externo poderá, como tal, ser considerada um argumento importante a favor da integração entre as abordagens contingencial e ecológica. 
Para que essa articulação entre perspectivas e níveis de análise possa ser levada a cabo de forma conseqüente, é necessário sobretudo que a ecologia organizacional passe da posição de determinismo ambiental para a de aceitação dos efeitos interativos entre a organização e o ambiente externo. Em tal quadro teórico seria possível entender os esforços adaptativos da organização como tentativas individuais de sobrevivência e contribuições para a moldagem do ambiente externo organizacional, o qual passaria a ser entendido não como uma força supra-organizacional, mas como o resultado da articulação complexa das ações das organizações que compõem a população. Nesse quadro poderiam também ser incorporadas outras teorias que Donaldson (1995) toma como anti-management: a dependência de recursos (Pfeffer e Salancik, 1978) procuraria explicar o modo como os gestores tentam moldar o ambiente externo conforme os desejos das organizações, representando, por isso, uma espécie de inversão das prioridades da teoria contingencial, embora mantendo o mesmo objetivo (isto é, a adequação da articulação organização-ambiente externo), e a perspectiva institucionalista (Di Maggio e Powell, 1983) procuraria explicar a importância da aprendizagem por imitação na sobrevivência organizacional.

É nossa convicção que as abordagens referidas podem ser reconciliadas num quadro teórico integrativo de base funcionalista, mas receptivo à análise de for- mas de adaptação voltadas para o exterior e não apenas para a análise dos componentes internos da adaptação organizacional: o ajustamento ao ambiente externo do triângulo estratégia/estrutura/processo não anula a importância da ação política nem invalida a possibilidade de adoção de soluções testadas com sucesso na concorrência.

Tendo por base a argumentação de Donaldson (1995), defendeu-se aqui a possibilidade de integrar num quadro funcionalista englobante as teorias ecológica e contingencial. No entanto, para que essa integração possa ser passada à prática, é imperioso que a teoria ecológica seja entendida a partir de um cunho de gestão e não tanto sociológico. A sua atual tonalidade sociológica leva-nos a atribuir um papel modesto à ação da gestão (embora, como aqui se procurou demonstrar, os elementos de gestão nela estejam presentes), tonalidade essa que é de alguma forma incompatível com o paradigma funcionalista dominante e a transforma numa "bolsa enquistada", com forte consenso paradigmático, é certo, mas em rota de colisão mais ou menos evidente não só com o paradigma dominante, como também com todas as perspectivas que aceitem como válido o princípio de que a ciência organizacional deve não apenas ajudar a compreender as organizações, mas também ensinar a geri-las de forma mais adequada aos seus próprios interesses e aos interesses mais vastos da sociedade.

\section{REFERÊNCIAS BIBLIOGRÁFICAS}

BAUM, J. A. C., SINGH, J. V. Organization-environment coevolution. In: BAUM, J. A. C., SINGH, J. V. (Eds.). Evolutionary dynamics of organizations. New York: Oxford University Press, 1994. p. 379-401.

BOEKER, W. Organizational strategy: an ecological perspective. Academy of Management Journal, v. 34, n. 3, p. 613-35, 1991.

BURGELMAN, R. A. Strategy-making and organizational ecology: a conceptual integration. In: SINGH, J. V. (Ed.) Organizational evolution: new directions. Beverly-Hills: Sage, 1990. p. 164-181.

CROZIER, M., FRIEDBERG, E. L'acteur et le système. Paris: Seuil, 1977.

CUNHA, M. P. Organizações, recursos e a luta pela sobrevivência. RAE - Revista de Administração de Empresas, v. 33, n. 5, p. 34-47, set./out. 1993.

Di MAGGIO, P., POWELL, W. W. The iron cage revisited: institucional isomorphism and collective rationality in organizational fields. American Sociological Review, v. 48, p.147-60, 1983
DONALDSON, L. American anti-management theories of organization: a critique of paradigm proliferation. Cambridge: Cambridge University Press, 1995.

FISCHMANn, A. A. Algumas aplicações de ecologia de empresas. Tese (Doutorado) - Faculdade de Economia e Administração, USP, 1972.

GARCIA-MARQUES, T. Decisão: racionalidade e intuição. Comportamento Organizacional e Gestão, v. 1, n. 1, p. 67-76, 1995.

GRUPO DE LISBOA. Limites à competição. Mem-Martins: Europa-América, 1994.

HANNAN, M. T., FREEMAN, J. The population ecology of organizations. American Journal of Sociology, v. 82, p.924-64, 1977

HANNAN, M. T., FREEMAN, J. Structural inertia and organizational change. American Sociological Review, v. 49, p.149-64, 1984

HANNAN, M. T., FREEMAN, J. Organizational ecology. Cambridge: Harvard University Press, 1989.

McKELVEY, B., ALDRICH, H. Populations, natural selection and applied organizational science. Administrative Science Quarterly, v. 28, p. 101-28, 1983.
PFEFFER, J. Barriers to the advance of organizational science paradigm development as a dependent variable. Academy of Management Review, v. 18, p. 599-620, 1993.

PFEFFER, J., SALANCIK, G. R. The external control of organizations. New York: Harper e Row, 1978.

SCHNEIDER, B. Interactional psychology and organizational behavior. In: CUMMINGS, L. L., STAW, B. M. (Eds.). Research in organizational behavior. Greenwhich: JAl Press, 1983. v. 5, p.1-31.

VERHALLEN, T. M. M. Scarcity. unavailability and behavioral costs. Dissertation (Doctoral) - Tilburg University, Tilburg, The Netherlands, 1984. (Unpublished).

WEISS, H. M., ILGEN, D. R. Routinized behaviour in organizations. The Journal of Behavioral Economics, v. 14 p.57-67, Winter 1985.

YOUNG, R. C. Is population ecology a useful paradigm for the study of organizations? American Journal of Sociology, v. 94, p.1-24, 1988.

ZACCARELLI, S. B., FISCHMANN, A. A., LEME, R. A. S. Ecologia de empresas: um estudo do ambiente empresarial. São Paulo: Atlas, 1980

NOTAS

1. Apesar do papel normalmente conferido ao artigo de Hannan e Freeman, o tema já havia sido abordado em trabalhos anteriores, a saber, na tese de doutorado de Fischmann (1972).
2. 0 Grupo de Lisboa, composto por 19 membros provenientes da Europa Ocidental, Japão e América do Norte, procede à análise do papel da competição no mundo atual e, rejeitando a filosofia do competitivismo, dedicase à tentativa de criação de novas formas de regulação mundial. 